\title{
Produção de serapilheira e devolução de macronutrientes em um povoamento de Eucalyptus saligna (F. Muell) $)^{1}$
}

\author{
Simone Martini Salvador ${ }^{2}$, Catarine Barcellos Consensa ${ }^{3}$, Elias Frank de Araújo ${ }^{4}$
}

\begin{abstract}
Resumo: A serapilheira é a principal via de transferência de nutrientes das plantas para o solo em ecossistemas florestais. Assim, o estudo da produção de serapilheira é fundamental para compreender o funcionamento destes ecossistemas. O presente estudo objetivou a avaliação da produção de serapilheira, a devolução de macronutrientes e a correlação com variáveis climáticas, em um povoamento de Eucalyptus saligna em São Gabriel - Rio Grande do Sul. Foram instaladas 4 parcelas de $23 \mathrm{~m}$ x $26 \mathrm{~m}$ e em cada uma delas foram distribuídos 4 coletores com $0,5 \mathrm{~m}^{2}$ de área. Para a quantificação de galhos grossos (diâmetro >0,5 cm), em cada parcela foram demarcadas três subparcelas de $3 \mathrm{~m} \mathrm{x} 2 \mathrm{~m}$, sobre o solo, delimitadas por uma árvore de diâmetro médio. As amostras foram coletadas quinzenalmente, separadas em galhos grossos, galhos finos (diâmetro $<0,5 \mathrm{~cm}$ ), folhas e miscelânea, após foram secas em estufa, pesadas, moídas e encaminhadas para análise química, onde foram determinados os teores dos macronutrientes. A produção anual de serapilheira foi de $9,93 \mathrm{Mg} \mathrm{ha}^{-1}$, sendo $54,0 \%$ folhas, 24,7\% galhos grossos, 11,2\% miscelânea e 10,1\% galhos finos. O aporte total de macronutrientes foi de 71,56 kg ha ${ }^{1}$ para o Ca, 45,15 $\mathrm{kg} \mathrm{ha}^{-1}$ de N, 38,93 kg ha-1 de K, 17,54 $\mathrm{kg} \mathrm{ha}^{-1}$ de Mg, 6,19 $\mathrm{kg} \mathrm{ha}^{-1}$ de S e 2,81 kg ha-1 de P.
\end{abstract}

Palavras - chave: Nutrição florestal; Solos florestais; Sustentabilidade florestal.

\section{Litterfall production and return of macronutrients of settlement in a Eucalyptus saligna (F. Muell)}

\begin{abstract}
Litterfall is the mainly route of plant nutrients transfer to the soil in forest ecosystems. Therefore the study of the litterfall is very important fundamental to understanding the functioning of these ecosystems. Given this importance, this study aimed to estimate litter production in Eucalyptus saligna stand, São Gabriel - RS. Were installed 4 plots of $23 \mathrm{~m}$ x 26 $\mathrm{m}$ in each of these plots, 4 litter collectors. For branches with a diameter bigger than $0.5 \mathrm{~cm}$, in each plot were demarcated aboveground three plots of $3 \mathrm{~m} \times 2 \mathrm{~m}$, bounded by an average diameter tree. Samples were collected fortnightly, sorted into thick branches, twigs (diameter of less than 0.5), leaves and miscellaneous, then were oven dried, weighty, and sent to the chemical analysis where it was determinate the content of macronutrients. During the twelve month period, litter production was $9,93 \mathrm{Mg} \mathrm{ha}^{-1}, 54.0 \%$ of leaves, $24.7 \%$ thick branches, $11.2 \%$ of miscellaneous and $10.1 \%$ of twigs. The overall contribution of macronutrients was 71,56 kg ha-1 of Ca, 45,15 $\mathrm{kg} \mathrm{ha}^{-1}$ of $\mathrm{N}, 38,93 \mathrm{~kg} \mathrm{ha}^{-1}$ of K, 17,54 kg ha- of Mg, 6,19 kg $\mathrm{ha}^{-1}$ of S and $2,81 \mathrm{~kg} \mathrm{ha}^{-1}$ of P.
\end{abstract}

Keywords: Forestry nutrition; Forestry soils; Forestry sustainability.

\footnotetext{
${ }^{1}$ Recebido em 05.09.2014 e aceito para publicação como artigo científico em: 26.01.2015.

${ }^{2}$ Engenheira Florestal, Mestranda do Programa de Pós-graduação em Engenharia Florestal, Centro de Ciências Rurais, Universidade Federal de Santa Maria. Bolsista do CNPq. E-mail: <simone.ufsm@gmail.com>.

${ }^{3}$ Engenheira Florestal, M.Sc., Doutoranda do Programa de Pós-graduação em Engenharia Florestal, Centro de Ciências Rurais, Universidade Federal de Santa Maria. Bolsista Capes. E-mail: <catarineconsensa@ gmail.com>.

${ }^{4}$ Engenheiro Florestal da empresa CMPC - Celulose Rio Grandense. E-mail: <efaraujo@cmpcrs.com.br〉.
} 


\section{Introdução}

A demanda por produtos florestais cresce a cada ano e, atualmente, no cenário socioeconômico brasileiro, a silvicultura passou a ter destaque no setor de produção, devido aos seus benefícios econômicos, sociais e ambientais. Porém, ainda são muitos os desafios a serem enfrentados pelas empresas florestais, uma vez que a produção florestal é entendida como parte da gestão ambiental, podendo diminuir a competitividade das empresas do setor, que não podem utilizar toda a potencialidade do recurso florestal brasileiro, para garantir respostas sociais e econômicas satisfatórias (MACHADO et al., 2008).

O manejo eficiente de plantações comerciais está ligado à nutrição florestal com ênfase nos processos de ciclagem de nutrientes, sendo necessário para tanto, que ocorra um fluxo contínuo entre o que é depositado sobre o solo e o que é assimilado pelas raízes, sendo que o conhecimento desta dinâmica nutricional via produção de serapilheira em sítios florestais, é vital tanto para manter a produção contínua e sustentada da floresta, bem como, o acúmulo de nutrientes, possibilitando a previsão de situações críticas na produtividade florestal e nas características químicas do solo (VIERA, 2012).

Os processos de absorção de nutrientes pelas plantas, translocação interna entre os tecidos vegetais e a transferência dos nutrientes acumulados na serapilheira para o solo, a atmosfera e a hidrosfera representam a ciclagem de nutrientes (ESPIG, 2009). Em plantações de florestas comerciais, esta ciclagem pode ser analisada por meio da compartimentalização da biomassa acumulada nos diferentes estratos e a quantificação das taxas de nutrientes que se movimentam entre seus compartimentos, pela produção de serapilheira, sua decomposição, lixiviação e outros (SCHUMACHER et al., 2003).

A serapilheira é formada por material vegetal da parte aérea das plantas, como folhas, frutos, sementes, flores, galhos e cascas. Segundo Schumacher e Hoppe (1998), no interior de uma floresta, a serapilheira depositada sobre o solo desempenha papel fundamental na manutenção das condições ideais para o processo de infiltração d'água, bem como da fertilidade e dos níveis de nutrientes no solo, uma vez que a serapilheira assume o papel de estoque potencial de nutrientes para o sistema. Isso é devido à sua decomposição, que resulta no acúmulo da matéria orgânica no solo, na liberação de seus nutrientes para a biota e na dissipação de parte do dióxido de carbono, sendo um processo que mantém a fertilidade e a produtividade do sítio.

É devido à eficiência do processo de ciclagem que ocorre nas camadas e horizontes mais superficiais do solo que a maior parte das florestas tropicais e subtropicais mantêm sua alta produtividade, mesmo em solos com baixa disponibilidade de nutrientes (SCHEER, 2008).

O presente trabalho objetivou a avaliação da produção de serapilheira, a devolução de macronutrientes e a correlação com variáveis climáticas, em um povoamento de Eucalyptus saligna, no município de São Gabriel - Rio Grande do Sul.

\section{Materiais e métodos}

Caracterização da área de estudo

O presente estudo foi realizado na área experimental da Fazenda Ponta das Canas, pertencente à Empresa CMPC Celulose Riograndense, no município de São Gabriel RS. Na região, segundo a classificação de Köppen, o clima é do tipo Cfa, caracterizado como subtropical, em que a temperatura do mês mais frio oscila entre $-3{ }^{\circ} \mathrm{C}$ e $18^{\circ} \mathrm{C}$ e a média do mês mais quente é superior a $22{ }^{\circ} \mathrm{C}$. A precipitação pluviométrica média anual é de 1.356 mm (MORENO, 1961).

O solo da região é classificado como Cambissolo Háplico distrófico, com textura franco arenosa, tendo como características marcantes a presença de um horizonte $\mathrm{B}$ incipiente e baixo gradiente textural entre os horizontes (CAVARARO et al., 2007).

Segundo a Comissão de Química e Fertilidade do Solo - RS/SC (2004), o solo 
apresenta teor de matéria orgânica baixo $(\leq 2,5)$;

o pH em água é considerado muito baixo $(\leq 5,0)$;

o teor de Ca trocável é considerado baixo $(<2,0$ $\left.\mathrm{cmol} \mathrm{cdm}^{-3}\right)$; o teor de $\mathrm{Mg}$ trocável é considerado

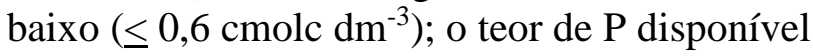
é considerado muito baixo após os primeiros 20 cm de profundidade $\left(\leq 5,0 \mathrm{mg} \mathrm{dm}^{-3}\right)$ e o teor de $\mathrm{K}$ trocável é considerado de médio a alto (30 $90 \mathrm{mg} \mathrm{dm}^{-3}$ ). Na Tabela 1, podemos observar os atributos químicos do solo para o presente estudo.

Tabela 1: Atributos químicos do solo na área de estudo no município de São Gabriel - RS.

Table 1: Chemical properties of soil in the study area in the municipality of São Gabriel - RS.

\begin{tabular}{|c|c|c|c|c|c|c|c|c|c|c|}
\hline \multirow{2}{*}{ Profundidade } & $\mathrm{Ag}$ & $\mathrm{MO}$ & \multirow{2}{*}{$\begin{array}{c}\mathrm{pH} \\
\left(\mathrm{H}_{2} \mathrm{O}\right)\end{array}$} & $\mathrm{Al}$ & $\mathrm{Ca}$ & $\mathrm{Mg}$ & $\mathrm{P}^{*}$ & $\mathrm{~K}^{*}$ & $\mathrm{Al}+\mathrm{H}$ & $\mathrm{CTC}_{\mathrm{pH} 7}$ \\
\hline & \multicolumn{2}{|c|}{$\%$} & & \multicolumn{3}{|c|}{$\mathrm{cmol}_{\mathrm{c}} \mathrm{dm}^{-3}$} & \multicolumn{2}{|c|}{$\mathrm{mg} \mathrm{dm}^{-3}$} & \multicolumn{2}{|c|}{$\%$} \\
\hline $0-20$ & 12,6 & 1,7 & 4,1 & 2,0 & 0,6 & 0,4 & 13,2 & 51,6 & 9,2 & 10,3 \\
\hline $20-40$ & 25,3 & 1,7 & 4,3 & 3,0 & 0,8 & 0,2 & 3,3 & 42,7 & 13,3 & 14,4 \\
\hline $40-60$ & 25,3 & 1,3 & 4,4 & 2,6 & 1,1 & 0,2 & 2,6 & 30,8 & 11,6 & 13,0 \\
\hline $60-80$ & 8,3 & 0,9 & 4,7 & 1,1 & 1,6 & 0,3 & 2,9 & 37,5 & 4,6 & 6,6 \\
\hline 80-100 & 6,3 & 0,5 & 4,8 & 0,8 & 1,7 & 0,5 & 2,6 & 36,1 & 3,1 & 5,4 \\
\hline
\end{tabular}

Ag =Argila; $\mathrm{MO}=$ Matéria Orgânica; V= Saturação de Bases; m= Saturação por Alumínio; * Extrator Mehlich ${ }^{-1}$

Para implantação do povoamento foi realizado o preparo do solo por meio da subsolagem com uma haste à $50 \mathrm{~cm}$ de profundidade. Concomitantemente ao preparo de solo, foi realizado adição de $2000 \mathrm{~kg} \mathrm{ha}^{-1}$ de calcário á lanço $+500 \mathrm{~kg} \mathrm{ha}^{-1}$ de fosfato reativo no sulco de preparo $+100 \mathrm{~g} / \mathrm{pl}$ de NPK 06:30:06 no plantio em coveta lateral $+200 \mathrm{~g} / \mathrm{pl}$ de NPK 12:00:20 com 0,5\% de Boro aos 120 dias +200 $\mathrm{kg} \mathrm{ha}^{-1}$ de NPK 12:00:20 aos 12 meses. Após a implantação do povoamento de Eucalyptus saligna com espaçamento de $3,5 \mathrm{~m} \times 2,75 \mathrm{~m}$, realizou-se alguns tratos silviculturais na área como uma capina química em área total com glifosato (scout - $2 \mathrm{~kg} \mathrm{ha}^{-1}$ ) + aplicação de préemergente (GOAL BR - 41 ha $^{-1}$ ) na linha +2 tratos culturais com glifosato aos 90 dias e aos 9 meses.

Metodologia de estudo

O estudo teve início em fevereiro de 2011, quando o povoamento encontrava-se com 53 meses de idade e foi realizado até janeiro de 2012, aos 65 meses. Para a quantificação da serapilheira, primeiramente foram demarcadas e instaladas 4 parcelas aleatórias de $23 \mathrm{~m}$ x $26 \mathrm{~m}$ e, em cada uma destas, foram distribuídos, sistematicamente, 4 coletores, alocados em quatro diferentes posições: na linha do plantio, entrelinha, na diagonal (entre 4 árvores) e encostado no tronco da árvore. Os coletores foram formados por uma moldura quadrada de madeira com $0,50 \mathrm{~m}^{2}$ de área, com o fundo de tela de nylon com $1 \mathrm{~mm}$, suspensos por estacas de madeira, a 0,50 $\mathrm{m}$ do solo. Para a coleta dos galhos grossos (diâmetro superior a $0,5 \mathrm{~cm}$ ), foram demarcadas, em cada parcela, três subparcelas de $2 \mathrm{~m} \mathrm{x} 3 \mathrm{~m}$, sobre o solo, as quais tinham, ao centro, a árvore com DAP mais próximo a média do povoamento.

$\mathrm{O}$ material foi coletado quinzenalmente (visando reduzir a perda de nutrientes por lixiviação) e homogeneizado em amostras mensais. Após, foi encaminhado para o laboratório, onde foi separado nas frações: folhas, galhos finos, galhos grossos e miscelânea. Posteriormente, as frações foram colocadas em estufa de circulação e renovação de ar a uma temperatura de $70{ }^{\circ} \mathrm{C}$ para secagem até massa constante. Para quantificação do material coletado em cada uma das parcelas, foram feitas as pesagens individuais (em balança de precisão de $0,01 \mathrm{~g}$ ) da serapilheira total e das 
frações separadas, formando assim uma amostra composta. Para estimar o valor médio de serapilheira depositado em cada parcela, calculou-se a média aritmética da deposição para cada fração e total de serapilheira produzida.

Após pesadas, as amostras foram moídas em moinho do tipo Willey para posterior análise química dos macronutrientes $(\mathrm{N}, \mathrm{P}, \mathrm{K}, \mathrm{Ca}, \mathrm{Mg}$ e $\mathrm{S})$, A metodologia de análise de amostras de tecido vegetal foi adaptada de Miyazawa et al. (1999) e Tedesco et al. (1995). A determinação de $\mathrm{N}$ foi feita pelo método Kjeldahl em aparelho Büchi, modelo Autokjeldahl K-370, com digestão sulfúrica $\left(\mathrm{H}_{2} \mathrm{SO}_{4}+\mathrm{H}_{2} \mathrm{O}_{2}\right)$ prévia. Para $\mathrm{P}, \mathrm{K}, \mathrm{Ca}, \mathrm{Mg}$ e $\mathrm{S}$ foi feita digestão nítrico perclórica $\left(\mathrm{HNO}_{3}+\mathrm{HClO}_{4}\right.$ na razão 3:1). A determinação de $\mathrm{Ca}$ e $\mathrm{Mg}$ foi por espectrofotometria de absorção atômica, em aparelho Perkin Elmer modelo Analyst 200, K por fotometria de chama, em aparelho Digimed modelo DM-62, P por espectrofotometria, em aparelho Unico, modelo 2100, e S por turbidimetria, no mesmo equipamento.

$\mathrm{O}$ aporte dos nutrientes foi calculado multiplicando-se a concentração dos nutrientes pela deposição em cada fração.

Visando o estabelecimento de correlações entre a produção de serapilheira e variáveis meteorológicas, a precipitação pluviométrica foi coletada através de três coletores da precipitação global (em área aberta próxima ao povoamento). Em relação à temperatura, os dados foram obtidos junto a base de dados da empresa CMPC (2011), que disponibilizou valores médios mensais das temperaturas mínimas e máximas (a temperatura média mensal foi obtida pela média das temperaturas mínimas e máximas), da
Estação Meteorológica de Observação de Superfície Automática de São Gabriel, RS, localizada a $2 \mathrm{~km}$ do local, bem como os dados de Umidade Relativa do Ar e de Velocidade do Vento.

De posse dos dados mensais de deposição de serapilheira, teores e quantidades dos macronutrientes, foi realizada análise de variância (ANOVA) para cada variável, considerando o delineamento experimental de blocos ao acaso com quatro repetições. Nos casos onde a ANOVA mostrou diferença estatística significativa, foi feita a comparação de médias pelo teste de Tukey. Os dados de deposição mensal de serapilheira foram correlacionados com os valores de precipitação, temperatura, umidade do ar e velocidade média do vento, utilizando-se análise de correlação simples. Todas as análises estatísticas foram realizadas com o auxílio do programa estatístico SAS, ao nível de 5\% de probabilidade de erro.

\section{Resultados e Discussão}

Produção de serapilheira

A produção anual de serapilheira foi de 9,93 $\mathrm{Mg} \mathrm{ha}^{-1}$, com contribuição de folhas > galhos grossos > miscelânea > galhos finos. Todas as frações apresentaram elevados coeficientes de variação, ratificando a heterogeneidade na distribuição mensal sobre o solo florestal (Tabela 2), corroborando com Kleinpaul et al. (2005), os quais indicam que a distribuição de galhos na serapilheira ocorre de forma heterogênea.pH

Tabela 2: Frações da serapilheira produzida anualmente em um povoamento de Eucalyptus saligna aos 4,4 anos de idade. Table 2: Litterfall fractions yearly production in a stand of Eucalyptus saligna the 4.4 years of age.

\begin{tabular}{cccccc}
\hline Variáveis/ Frações & Folha & Galho Fino & Galho Grosso & Miscelânea & Total \\
\hline Biomassa $\left(\mathrm{kg} \mathrm{ha}^{-1}\right)$ & $5367,30^{\mathrm{a}}$ & $1001,68^{\mathrm{b}}$ & $2449,19^{\mathrm{ab}}$ & $1116,81^{\mathrm{b}}$ & 9934,98 \\
$\%$ & 54,0 & 10,1 & 24,7 & 11,2 & 100 \\
Desvio-padrão & 331,46 & 55,97 & 329,38 & 128,67 & - \\
CV $(\%)$ & 74,11 & 67,05 & 161,38 & 138,26 & - \\
\hline
\end{tabular}

*Médias seguidas pela mesma letra na horizontal, não diferem entre si pelo Teste de Tukey a 5\% de probabilidade de erro. 
Viera et al. (2014), estudando a dinâmica nutricional em um povoamento de Eucalyptus urophylla x Eucalyptus globulus, observaram que a produção de serapilheira foi crescente com o aumento da idade do povoamento, sendo 6,9 $\mathrm{Mg} \mathrm{ha}^{-1}$ aos seis anos e $8,5 \mathrm{Mg} \mathrm{ha}^{-1}$ aos nove anos, valor este semelhante quando comparado com o presente estudo. Já Zaia e Rodrigues (2004), analisando a ciclagem e balanço de nutrientes em povoamentos de eucalipto na Região Norte Fluminense aos seis anos de idade, encontraram uma deposição menor, sendo esta de 4,7 $\mathrm{Mg} \mathrm{ha}^{-1}$. Estas diferenças são influenciadas pela densidade do povoamento, espécie e variáveis climáticas.

Segundo Souza (2001), uma área de mata não minerada, onde foi realizado um estudo com as espécies Mimosa scabrella Benth. (Bracatinga) e Eucalyptus saligna F. Muell, a maior deposição anual de serapilheira foi encontrada na área com eucalipto, correspondente a $7,1 \mathrm{Mg}$ $\mathrm{ha}^{-1}$, seguido pela área de mata não minerada com 4,5 Mg ha ${ }^{-1}$ e pela bracatinga com 3,5 Mg $\mathrm{ha}^{-1}$, evidenciando uma maior produção de serapilheira em áreas com eucalipto, quando comparadas com outras espécies.

Na Figura 1, verifica-se a variação mensal na deposição de serapilheira produzida durante o período de fevereiro de 2011 a janeiro de 2012.

O mês com maior produção total de serapilheira foi janeiro de 2012, com um aporte de $1604,89 \mathrm{~kg} \mathrm{ha}^{-1}$ e o mês com menor deposição foi maio com $194,77 \mathrm{~kg} \mathrm{ha}^{-1}$. No mês de março ocorreu maior deposição de folhas, totalizando $1.106,89 \mathrm{~kg} \mathrm{ha}^{-1}$, e a menor deposição foi no mês de maio, com 108,25 $\mathrm{kg} \mathrm{ha}^{-1}$.

Para a fração miscelânea, a maior deposição ocorreu no mês de dezembro, com 479,33 $\mathrm{kg} \mathrm{ha}^{-}$ ${ }^{1}$, e a menor deposição ocorreu no mês de outubro, com 10,56 kg ha-1. Para a fração galhos finos o mês que teve maior representatividade foi agosto, com 213,00 kg ha ${ }^{-1}$ e com menor produção foi o mês de maio, com $11,41 \mathrm{~kg} \mathrm{ha}^{-1}$. Para os galhos grossos, o mês com maior produção foi janeiro, com $1214,37 \mathrm{~kg} \mathrm{ha}^{-1}$, já no em março a produção foi de $13,46 \mathrm{~kg} \mathrm{ha}^{-1}$, sendo este o mês com menor produção.

No estudo realizado por Corrêa et al. (2011), na região do Pampa Gaúcho, os autores verificaram que a deposição de serapilheira apresentou variação ao longo dos meses, sendo que novembro foi o mês com maior $\left(700 \mathrm{~kg} \mathrm{ha}^{-}\right.$ $\left.{ }^{1}\right)$ e julho o de menor deposição $\left(73 \mathrm{~kg} \mathrm{ha}^{-1}\right)$, dados da mesma ordem de variação verificada no presente estudo.

Esses autores salientam ainda que, no povoamento com 1,4 anos de idade, foram depositados aproximadamente 4,1 $\mathrm{Mg} \mathrm{ha}^{-1}$ ano $^{-1}$ de serapilheira, com a fração folhas contribuindo com uma deposição média de 93\%; miscelânea, com uma média de $6 \%$ e galhos grossos, com uma média de 1\%, valores diferentes do encontrado no presente estudo, onde o componente folhas contribui com $54 \%$ da serapilheira total depositada sobre o piso florestal, devido ao fato de que, com o avançar da idade do povoamento, as copas começam a competir entre si por espaço, diminuindo a produção de folhas e, consequentemente, havendo um decréscimo na produção deste componente da serapilheira e um incremento relativo na deposição de galhos.

Segundo Caldeira (2008), a produção de serapilheira varia em função da procedência, da espécie, da cobertura florestal, do estágio sucessional, da idade, da época da coleta, do tipo de floresta e do local. Além desses fatores, outros como condições edafoclimáticas e regime hídrico, clima, sítio, sub-bosque, manejo silvicultural, proporção de copa, bem como a taxa de decomposição e distúrbios naturais como fogo e ataque de insetos ou artificiais como remoção da serapilheira e cultivos, ocorridos na floresta ou no povoamento, também influenciam na produção e no acúmulo de serapilheira.

Em um estudo realizado por Andrade, Costa e Faria (2000), com espécies leguminosas arbóreas, encontrou-se a maior deposição mensal no período onde ocorreu uma diminuição da precipitação e da temperatura, de fevereiro a junho, o que poderia estimular as plantas a aumentarem a queda de material senescente. Como forma de defesa, as plantas tendem a diminuir a área foliar, eliminando suas folhas mais velhas, o que, consequentemente, fará aumentar a camada de serapilheira que cobre o 
piso florestal.
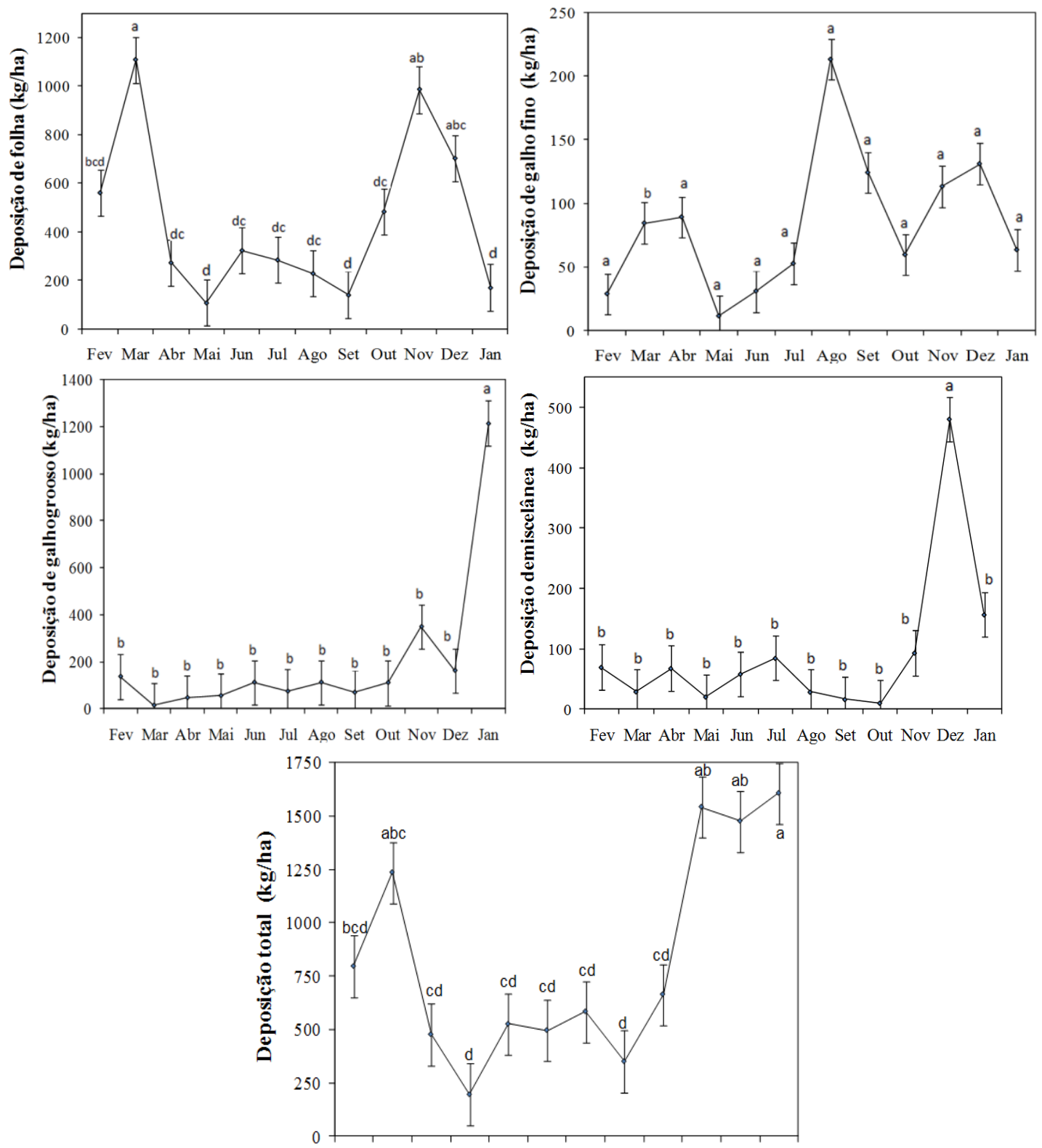

Fev Mar Abr Mai Jun Jul Ago Set Out Nov Dez Jan

Letras diferentes, em cada gráfico, indicam diferenças significativas entre os meses de deposição, ao nível de 5\% de significância, pelo teste de Tukey.

Figura 1: Deposição mensal das frações da serapilheira em um povoamento de Eucalyptus saligna aos 4,4 anos de idade. Figure 1: Monthly deposition of litterfall fractions of in a Eucalyptus saligna stand the 4.4 years of age.

Ainda, Schumacher et al. (2003) salientam que a deposição de serapilheira é sazonal, com picos durante o verão e menores produções no inverno, da mesma forma como Balieiro et al. (2004) verificaram que as maiores deposições de serapilheira em plantios de Pseudosamanea guachapele e Eucalyptus grandis predominaram nos meses de dezembro, janeiro e fevereiro.

No presente estudo, verificou-se que a deposição mais intensa é concomitante com o período de maior atividade fisiológica (meses com temperaturas mais elevadas), ocorrendo à 
troca da folhagem senescente. Dias et al. (2002) ressaltam ainda que o estresse hídrico desencadeia uma série de eventos fisiológicos na planta, acarretando, no final, a abscisão das folhas, o que é corroborado por Kramer e Kozlowski (1960), os quais justificam que a queda das folhas é causada pela senescência, resultante de uma série de processos metabólicos ligados à fisiologia de cada espécie e também pelos estímulos vindos do ambiente, como fotoperíodo, temperatura, etc.

Na Tabela 3 é possível verificar a correlação das variáveis climáticas com a deposição de serapilheira do presente trabalho.

Tabela 3: Correlação de Pearson, ao nível de 5\% de significância, entre a deposição mensal de serapilheira e suas frações em um povoamento de Eucalyptus saligna aos 4,4 anos de idade e variáveis meteorológicas em São Gabriel - RS.

Table 3: Pearson Correlation at the 5\% level of significance, between monthly litterfall production and it's in a Eucalyptus saligna stand the 4.4 years of age, and meteorological variables in São Gabriel - RS.

\begin{tabular}{cccccc}
\hline Variáveis Climáticas & Serapilheira & \multicolumn{4}{c}{ Fração } \\
\cline { 3 - 6 } & Total & Folhas & Galhos finos & Galho Grosso & Miscelânea \\
\hline Temperatura Mínima média $\left({ }^{0} \mathrm{C}\right)$ & 0,37 & 0,13 & $-0,04$ & 0,19 & 0,03 \\
Temperatura Máxima média $\left({ }^{0} \mathrm{C}\right)$ & 0,63 & 0,24 & 0,01 & 0,31 & 0,17 \\
Temperatura Média $\left({ }^{0} \mathrm{C}\right)$ & 0,60 & 0,26 & $-0,01$ & 0,27 & $-0,15$ \\
Precipitação Global $(\mathrm{mm})$ & $-0,09$ & $-0,05$ & $-0,06$ & $-0,11$ & $-0,48$ \\
Umidade Relativa do Ar $(\%)$ & $-0,80$ & $-0,16$ & $-0,10$ & 0,29 \\
Velocidade do Vento $(\mathrm{m} / \mathrm{s})$ & 0,52 & 0,28 & 0,32 & 0,11 \\
\hline
\end{tabular}

A temperatura média e a umidade relativa tiveram as maiores correlações com a deposição de serapilheira, sendo $r=0,60$ e $r=-0,80(p<$ $0,05)$, respectivamente. A correlação positiva com a tempertura média mostra que com o aumento da temperatura, aumenta a deposição de serapilheira e valor negativo da correlação com a umidade relativa significa que, à medida que aumenta a umidade relativa, diminui a deposição de serpilheira.

A correlação com a precipitação foi negativa $(\mathrm{r}=-0,09)$, o que indica que em períodos de menor disponibilidade hídrica, há aumento na deposição de serapilheira. Já a correlação com a velocidade do vento foi positiva com a deposição de serapilheira $(r=0,52)$, mostrando um efeito físico dessa variável na deposição na derrubada da serapilheira das árvores do povoamento.

Viera e Schumacher (2010) encontraram correlação da deposição de serapilheira apenas com a umidade relativa do ar em povoamentos de Pinus taeda L. em Cambará do Sul/RS. Também foi encontrada correlação significativa com dados de temperatura e não com dados de precipitação por Corrêa et al. (2013), ao estudarem a deposição de serapilheira em um povoamento de Eucalyptus dunnii sobre pastagem degradada. Barlow et al. (2007) encontraram correlação positiva entre a deposição mensal de folhas de E. urophylla, com 4,5 anos de idade e a precipitação mensal, em clima com estação seca na Amazônia.

A grande maioria das espécies de eucalipto desenvolveu mecanismos fisiológicos de adaptação a condições de déficit hídrico, ou seja, mecanismos de restrição do consumo de água nos períodos do ano quando a disponibilidade de água no solo é menor (MORA; GARCIA, 2000). Battaglia et al. (1998) mostraram que déficit de água e temperatura agiram interativamente nas diferenças em índices de área foliar entre plantios de E. globulus e E. nitens para toda a Austrália. Segundo Ladiges (1974), em períodos secos, o despendimento das folhas é comum em muitas espécies de eucalipto para reduzir a evapotranspiração.

\section{Devolução de Nutrientes}

\section{Concentrações de nutrientes}

$\mathrm{Na}$ Tabela 4 verificam-se as concentrações de macronutrientes para as diferentes frações formadoras da serapilheira produzida. De um 
modo geral, as concentrações de nutrientes galhos finos > galhos grossos > miscelânea. apresentaram-se na seguinte ordem: folhas >

Tabela 4: Concentração de nutrientes $\left(\mathrm{g} \mathrm{kg}^{-1}\right)$ nas frações da serapilheira produzida em um povoamento de Eucalyptus saligna com 4,4 anos de idade em São Gabriel-RS.

Table 4: Nutrient concentrations $\left(\mathrm{g} \mathrm{kg}^{-1}\right)$ in the fractions of the litterfall in a Eucalyptus saligna stand with 4.4 years old in São Gabriel-RS.

\begin{tabular}{ccccccc}
\hline \multirow{2}{*}{ Fração } & $\mathrm{N}$ & $\mathrm{P}$ & $\mathrm{K}$ & $\mathrm{Ca}$ & $\mathrm{Mg}$ & $\mathrm{S}$ \\
\cline { 2 - 6 } & \multicolumn{7}{c}{$\left(\mathrm{g} \mathrm{kg}^{-1}\right)$} & & \\
\hline \multirow{2}{*}{ Folhas } & $6,87^{\mathrm{a}}$ & $0,42^{\mathrm{a}}$ & $5,66^{\mathrm{a}}$ & $7,05^{\mathrm{b}}$ & $1,82^{\mathrm{a}}$ & $0,86^{\mathrm{a}}$ \\
& $( \pm 1,20)$ & $( \pm 0,09)$ & $( \pm 1,36)$ & $( \pm 0,94)$ & $( \pm 0,26)$ & $( \pm 0,16)$ \\
Galhos Finos & $2,39^{\mathrm{b}}$ & $0,31^{\mathrm{b}}$ & $3,70^{\mathrm{b}}$ & $10,31^{\mathrm{a}}$ & $1,93^{\mathrm{a}}$ & $0,38^{\mathrm{b}}$ \\
& $( \pm 0,29)$ & $( \pm 0,12)$ & $( \pm 0,86)$ & $( \pm 2,11)$ & $( \pm 0,39)$ & $( \pm 0,16)$ \\
Galhos Grossos & $1,58^{\mathrm{c}}$ & $0,13^{\mathrm{c}}$ & $1,01^{\mathrm{c}}$ & $9,84^{\mathrm{a}}$ & $1,47^{\mathrm{b}}$ & $0,32^{\mathrm{b}}$ \\
& $( \pm 0,17)$ & $( \pm 0,06)$ & $( \pm 0,34)$ & $( \pm 2,25)$ & $( \pm 0,23)$ & $( \pm 0,14)$ \\
Miscelânea & $2,86^{\mathrm{b}}$ & $0,11^{\mathrm{c}}$ & $1,07^{\mathrm{c}}$ & $3,26^{\mathrm{c}}$ & $1,99^{\mathrm{a}}$ & $0,41^{\mathrm{b}}$ \\
& $( \pm 0,61)$ & $( \pm 0,06)$ & $( \pm 0,66)$ & $( \pm 0,71)$ & $( \pm 0,26)$ & $( \pm 0,17)$ \\
\hline
\end{tabular}

**Médias seguidas pela mesma letra na vertical, não diferem entre si pelo Teste de Tukey a 5\% de probabilidade de erro. *** Valores entre parênteses referem-se ao desvio-padrão da média.

Verifica-se que o nitrogênio apresenta-se em maiores concentrações no componente folha, do que nas demais frações da serapilheira depositada no piso florestal, isso devido ao fato de este elemento participar da maioria das reações de metabolismo de compostos (aminoácidos, proteínas, aminas, amidas, vitaminas, etc.), as quais têm seu sítio de ocorrência principal nas folhas, em virtude da fotossíntese (MALAVOLTA, 1980).

Além disso, é na fração folhas onde o $\mathrm{K}$ é mais notável. Para Perez-Marin e Menezes (2008), o K é elemento móvel, sendo que a sua variabilidade nos teores da serapilheira tem relação com a variação da precipitação pluviométrica, pois quando a água da chuva toca as copas das árvores ele é lixiviado para o piso florestal, ocorrendo um enriquecimento deste elemento na serapilheira depositada sobre o solo. A ciclagem do $\mathrm{K}$ na relação solo-planta é mais rápida do que a de outros nutrientes, por se tratar de um cátion monovalente (CALDEIRA, 2008).

Segundo Viera (2010), essa tendência que a maioria dos nutrientes tem de se concentrar nas estruturas mais novas da planta é devida ao fato de as folhas possuírem maior atividade metabólica, necessitando dessa forma, maior disponibilidade de nutrientes. Além disso, o mesmo autor salienta ainda que são nessas regiões que se encontra a maioria das células vivas, responsáveis pela fotossíntese e pela transpiração.

Conforme Caldeira (1998), a concentração de nutrientes nas folhas das árvores é influenciada por diversos fatores tais como: condições de sítio, idade e posição das folhas na copa, época do ano e também entre procedências.

$\mathrm{Na}$ fração galhos finos encontrou-se os maiores teores de $\mathrm{Ca}$. O Ca é um elemento praticamente imóvel no floema das plantas e fica armazenado na forma de cristais, assim como o fato de o elemento ser um componente estrutural e fazer parte da lamela média da membrana celular (MALAVOLTA, 1980). Além disso, Borém e Ramos (2002) justificam que o enriquecimento de cálcio na serapilheira pode ser decorrente de uma liberação mais lenta deste elemento pelo material recém caído, o que poderia explicar-se assim a sua alta concentração na fração galhos finos.

\section{Quantidade de nutrientes}

A quantidade de $\mathrm{N}, \mathrm{P}, \mathrm{K}, \mathrm{Ca}, \mathrm{Mg}$ e $\mathrm{S}$ devolvidos consta na Tabela 5. Conforme um estudo realizado por Giácomo et al. (2012), a devolução de nutrientes via serapilheira no ambiente pode estar relacionada com a quantidade total aportada pela serapilheira. 
Estudando a produção de serapilheira e ciclagem de nutrientes de uma floresta estacional semidecidual em zona ripária em Botucatu - SP,
Vital et al. (2004) também verificaram que a transferência de nutrientes ao solo acompanhava a tendência de deposição da serapilheira.

Tabela 5: Quantidade de macronutrientes $\left(\mathrm{kg} \mathrm{ha}^{-1}\right)$ devolvidos através da serapilheira, para o período de fevereiro de 2011 a janeiro de 2012 em um povoamento de Eucalyptus saligna com 4,4 anos de idade em São Gabriel-RS.

Table 5: Amount of macronutrients $\left(\mathrm{kg} \mathrm{ha}^{-1}\right)$ in litterfall return for the period February 2011 to January 2012 in a Eucalyptus saligna stand with 4.4 years old in São Gabriel-RS.

\begin{tabular}{|c|c|c|c|c|c|c|}
\hline \multirow{2}{*}{ Fração } & $\mathrm{N}$ & $\mathrm{P}$ & $\mathrm{K}$ & $\mathrm{Ca}$ & $\mathrm{Mg}$ & $S$ \\
\hline & \multicolumn{6}{|c|}{$\left(\mathrm{kg} \mathrm{ha}^{-1}\right)$} \\
\hline Folhas & $35,73^{\mathrm{a} *}$ & $2,27^{a}$ & $31,25^{\mathrm{a}}$ & $37,72^{\mathrm{a}}$ & $9,56^{\mathrm{a}}$ & $4,67^{\mathrm{a}}$ \\
\hline Galhos finos & $2,48^{\mathrm{b}}$ & $0,26^{\mathrm{b}}$ & $3,71^{b}$ & $11,44^{\mathrm{b}}$ & $2,18^{b}$ & $0,36^{\mathrm{b}}$ \\
\hline Miscelânea & $3,05^{\mathrm{b}}$ & $0,07^{\mathrm{b}}$ & $1,16^{\mathrm{b}}$ & $3,04^{b}$ & $2,23^{b}$ & $0,46^{\mathrm{b}}$ \\
\hline Galhos grossos & $3,89^{\mathrm{b}}$ & $0,21^{\mathrm{b}}$ & $2,82^{b}$ & $19,36^{\mathrm{ab}}$ & $3,57^{\mathrm{b}}$ & $0,70^{\mathrm{b}}$ \\
\hline Total & 45,15 & 2,81 & 38,94 & 71,56 & 17,54 & 6,19 \\
\hline
\end{tabular}

* Médias seguidas pela mesma letra, na vertical, não diferem entre si pelo Teste de Tukey a 5\% de probabilidade de erro.

Embora no presente estudo, a quantidade de nutrientes seja consequência de suas concentrações e principalmente da produção total de serapilheira depositada por cada compartimento da planta, alterações na ordem de aporte de macronutrientes via deposição da serapilheira podem ser resultado da fertilização (Silva et al., 2011) e da diferença de idade e sistema silvicultural (Cunha et al., 2005). Conforme podemos observar na Tabela 5, é no componente folha que está a maior quantidade de $\mathrm{Ca}$, seguida pelas frações galhos grossos, galhos finos e miscelânea, sendo que somente o componente folhas contribuiu com $54 \%$ da serapilheira total que foi depositada pelo povoamento.

Kolm e Poggiani (2003), estudando a ciclagem de nutrientes em plantações de Eucalyptus grandis, também encontraram uma maior quantidade de cálcio em relação aos demais nutrientes, com $\mathrm{Ca}>\mathrm{N}>\mathrm{Mg}>\mathrm{K}>\mathrm{S}>$ $\mathrm{P}$, havendo uma inversão entre $\mathrm{Mg}$ e $\mathrm{K}$ para o presente trabalho, que apresentou a seguinte ordem de distribuição: $\mathrm{Ca}>\mathrm{N}>\mathrm{K}>\mathrm{Mg}>\mathrm{S}>$ P.

Em diversos estudos realizados por Haag (1985) é relatado que a quantidade de $\mathrm{N}$ é superior aos demais nutrientes, o que não ocorreu neste estudo. Isso pode estar relacionado à baixa disponibilidade deste nutriente no solo, como pode ser observado nos atributos químicos do solo do presente estudo (Tabela 1).

\section{Conclusões}

A serapilheira depositada sobre o solo florestal foi alta, principalmente no mês de janeiro e baixa no mês de maio, sendo que a fração folhas foi predominante na sua composição total. A precipitação pluviométrica foi a única variável meteorológica que apresentou pouca influência na deposição mensal de serapilheira. Além disso, o material depositado contribuiu significativamente para a manutenção do clico biogeoquímico através da elevada liberação de macronutrientes no sítio, os quais, neste estudo apresentaram a seguinte ordem de contribuição: $\mathrm{Ca}>\mathrm{N}>\mathrm{K}>\mathrm{Mg}>\mathrm{S}>$ P.

\section{Agradecimentos}

Agradecemos à empresa Celulose RioGrandense - CMPC, pelo apoio dado ao 
desenvolvimento do projeto concedendo a área particular para estudo e pelo apoio logísticofinanceiro, bem como, ao CNPq pela bolsa de pesquisa concedida ao primeiro autor.

\section{Referências}

ANDRADE, A.G.; COSTA, G. S.; FARIA, S. M. Deposição e decomposição da serapilheira em povoamentos de Mimosa caesalpiniifolia, Acacia manguim e Acacia holosericea com quatro anos de idade em Planossolo. Revista Brasileira de Ciência do Solo, v. 24, p. 777$785,2000$.

BALIEIRO, F. C. et al. Dinâmica da serapilheira e transferência de nitrogênio ao solo, em plantios de Pseudosamanea guachapele e Eucalyptus grandis. Pesquisa Agropecuária Brasileira, v.39, n.6, p.597-601, 2004.

BATTAGLIA, M. et al. Photosynthetic temperature response of Eucalyptus globulus and Eucalyptus nitens. Tree Physiology, n. 16, p. 81-89, 1996.

BORÉM, R. A. T.; RAMOS, D. P. Variação estacional e topográfica de nutrientes na serapilheira de um fragmento de Mata Atlântica.

Cerne, v. 8, n. 2, p. 042-059, 2002.

CALDEIRA, M. V. W. Quantificação de serapilheira e de nutrientes em uma Floresta Ombrófila Densa. Ciências Agrárias, v. 29, n. 1, p. 53-68, 2008.

CAVARARO, R. et al. Manual Técnico de Pedologia. Rio de Janeiro: IBGE, 2007. ed. 2, p. 316.

CORRÊA, R. S. et al. Deposição de serapilheira e macronutrientes em povoamento de Eucalyptus dunnii Maiden sobre pastagem natural degradada no Bioma Pampa. Scientia Forestalis, v. 41, n. 97, p. 065-074, 2013.

CUNHA, G.M. et al. Ciclagem de nutrientes em
Eucalyptus grandis W. Hill ex Maiden no norte fluminense. Revista Árvore, v.29, n.3, p.353363, 2005.

DELITTI, W. B. C. Estudos de ciclagem de nutrientes: instrumentos para a análise funcional de ecossistemas terrestres. Oecologia Brasiliensis, v. 1, p. 469-486, 1995.

DIAS, H. C. T. et al. Variação temporal de nutrientes na serapilheira de um fragmento de Floresta Estacional Semidecidual em Lavras, Minas Gerais - Brasil. Cerne, v. 8, n. 2, p. 1-16, 2002.

ESPIG, S. A. et al. Sazonalidade, composição e aporte de nutrientes da serapilheira em fragmento de mata atlântica. Revista Árvore, v. 33, n. 5, p. 949-956, 2009.

GIÁCOMO, R. G. et al. Aporte e decomposição de serapilheira em áreas de cerradão e mata mesofítica na Estação Ecológica de Pirapitinga MG. Ciência Florestal, v. 22, n. 4, p. 669- 680, 2012.

GONZALEZ, M.I.M.; GALLARDO, J.F. El efecto hojarasca: una revision. Anales de Edafologia y Agrobiologia, v. 41, p.1130-1157, 1986.

HAAG, H. P. Ciclagem de nutrientes em florestas tropicais. Campinas: Fundação Cargill, 1985. $144 \mathrm{p}$.

KLEINPAUL, I. S. et al. Suficiência amostral para coletas de serapilheira acumulada sobre o solo em Pinus elliottii Engelm, Eucalyptus sp. e Floresta Estacional Decidual. Revista Árvore, v. 29, n. 6, p. 965-972, 2005.

KOLM, L.; POGGIANI, F. Ciclagem de nutrientes em povoamentos de Eucalyptus grandis submetidos à prática de desbastes progressivos. Scientia Forestalis, n. 63, p. 7993, jun. 2003.

KRAMER, R. J.; KOSLOWSKI, T. T. 
Fisiologia das árvores. Tradução de Antonio M. A. Magalhães. Lisboa: Fundação Kalouste Gouldbenkian. 1960. p 745.

LADIGES, P.Y. Variation in drought tolerance in Eucalyptus viminalis Labill. Australian Journal Botany, v. 22, p. 489-500, 1974.

MACHADO, C.C. et al. O setor florestal brasileiro e a colheita florestal. In: MACHADO, C.C. Colheita Florestal. Viçosa: UFV, 2008. p 15-42.

MALAVOLTA, E. Elementos de nutrição mineral de plantas. São Paulo: Ceres, 1980. $251 \mathrm{p}$.

MELO, J. T.; RESCK, D. V. S. Retorno ao solo de nutrientes de serapilheira de pinus no cerrado do Distrito Federal. Boletim de Pesquisa e Desenvolvimento. Planaltina, DF: Embrapa Cerrados, 2002. 18 p.

MORA, A. L.; GARCIA, C. H. A cultura do eucalipto no Brasil. São Paulo: Sociedade Brasileira de Silvicultura, 2000. 107 p.

MORENO, J. A. Clima do Rio Grande do Sul. Porto Alegre: Secretaria da Agricultura, 1961. $73 \mathrm{p}$.

NEVES, E. J. M. et al. Deposição de serapilheira e de nutrientes de duas espécies da Amazônia. Boletim de Pesquisa Florestal, Colombo, n.43, p.47-60, 2001.

PEREZ-MARIN, A.M.; MENEZES, R.S.C. Ciclagem de nutrientes via precipitação pluvial total, interna e escoamento pelo tronco em sistema agroflorestal com Gliricidia sepium. Revista Brasileira de Ciência do Solo, v. 32, p. 2573-2579, 2008.

SCHUMACHER, M. V. et al. Retorno de Nutrientes via deposição de serapilheira em um povoamento de Acácia Negra (Acacia mearnsii De Wild.) no Estado do Rio Grande do Sul. Revista Árvore, v. 27, n. 6, p.791-798, 2003.
SCHUMACHER, M. V.; HOPPE, J. M. A floresta e a água. Porto Alegre: Pallotti, $1998.70 \mathrm{p}$.

SILVA, P.H.M. et al. Applying sewage sludge to Eucalyptus grandis plantations: effects on biomass production and nutrient cycling through litterfall. Applied and Environmental Soil Science, v. 2011, p.1-11, 2011.

SOUZA, J. A.; DAVIDE, A. C.; Deposição de serapilheira e nutrientes em uma mata não minerada e em plantações de Bracatinga (Mimosa scrabella) e de Eucalipto (Eucalyptus saligna) em áreas de mineração de bauxita. Cerne, v. 7, n. 1, p. 101-113, 2001.

VIERA, M. Crescimento inicial e produtividade em plantios monoespecíficos e mistos de Eucalyptus urograndis e Acacia mearnsii em sistema agrossilvicultural. 2010. 141 f. Dissertação (Mestrado em Engenharia Florestal) - Universidade Federal de Santa Maria, Santa Maria, 2010.

VIERA, M. et al. Conteúdo de nutrientes na serapilheira acumulada em povoamentos de Eucalyptus grandis, E. urophylla e E. cloeziana, no município de Santa Maria-RS. In: $5^{\circ}$ SIMPÓSIO DE PÓS-GRADUAÇÃO EM CIÊNCIAS FLORESTAIS, 2008, Brasília. Anais... Brasília, DF, 2008. p. 342.

VIERA, M. et al. Deposição de Serapilheira e Nutrientes em Plantio de Eucalyptus urophylla $\times$ E. globulus. Floresta e Ambiente, v. 21, n.3, p. 327-338, 2014.

VITAL, A. R. T. et al. Produção de serapilheira e ciclagem de nutrientes de uma floresta estacional semidecidual em zona ripária. Revista Árvore, v. 28, n. 6, p. 793 - 800, 2004.

ZAIA, F. C.; GAMA-RODRIGUES, A. C. Ciclagem e balanço de nutrientes em povoamentos de eucalipto na Região Norte Fluminense. Revista Brasileira de Ciência do Solo, v. 28, n. 5, p. 843-852, 2004. 